Eos, Vol. 95, No. 34, 26 August 2014

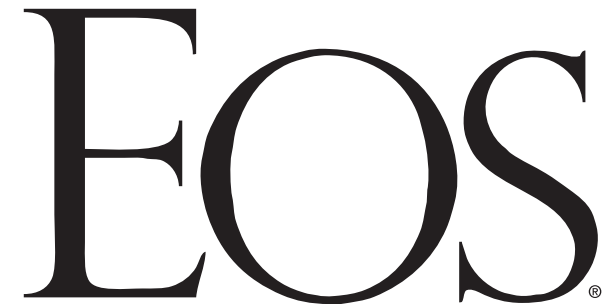

EOS, TRANSACTIONS, AMERICAN GEOPHYSICAL UNION

\section{VOLUME 95 NUMBER 34}

26 August 2014

PAGES 305-312

\title{
Cold Water and High Ice Cover on Great Lakes in Spring 2014
}

\section{PAGES 305-306}

Very cold temperatures across much of North America caused by the recent anomalous meridional upper air flow-commonly referred to in the public media as a polar vortex (for details, see Blackmon et al. [1977] and National Climatic Data Center, State of the climate: Synoptic discussion for January 2014, http://www.ncdc.noaa.gov/sotc/synoptic/ 2014/1) — have contributed to extreme hydrologic conditions on the Great Lakes. The Great Lakes are the largest system of lakes and the largest surface of freshwater on Earth-Lake Superior alone is the single largest lake by surface area.

Data collected and compiled by the Canadian Ice Service, the National Ice Center, the National Oceanic and Atmospheric Administration (NOAA) CoastWatch Program [Leshkevich et al., 1996], and the NOAA Great Lakes Ice Atlas [Assel, 2003; Wang et al., 2012a] indicate that very cold surface water temperatures and a relatively high areal extent of ice cover persisted across the Great Lakes well into May 2014. (Lake Superior wasn't ice free until 6 June, according to the National Ice Center.) Comparable ice cover across the Great Lakes for the same time of year has never been seen in the 40 years of recorded data.

At the end of April 2014, for example, roughly $23 \%$ of Lake Huron and $10 \%$ of Lake Michigan were covered in ice, whereas more than half of Lake Superior (roughly 51\%) was covered in ice (Figure 1). Prior to 2014, the highest percentage of late spring ice cover on Lake Superior was recorded (at roughly 30\%) in April 1979 (Figure 2); at that time, ice cover on the other Great Lakes was at or very close to $0 \%$. At no time in the 40 -year record has there been significant ice cover on Lakes Michigan, Erie, and Ontario in late April, and in only a few years has significant

By A. H. Clites, J. Wang, K. B. CAMPBell, A. D. Gronewold, R. A. Assel, X. BAi, And G. A. LESHKEVICH ice cover been reported in late April on Lake Huron.

Although spring 2014 conditions on the Great Lakes contrast sharply with those of the 40-year record, they are particularly unusual relative to conditions over the past 15 years, a period scientists believe to have been strongly influenced by the 1997-1998 El Niño [McPhaden, 1999] and subsequent

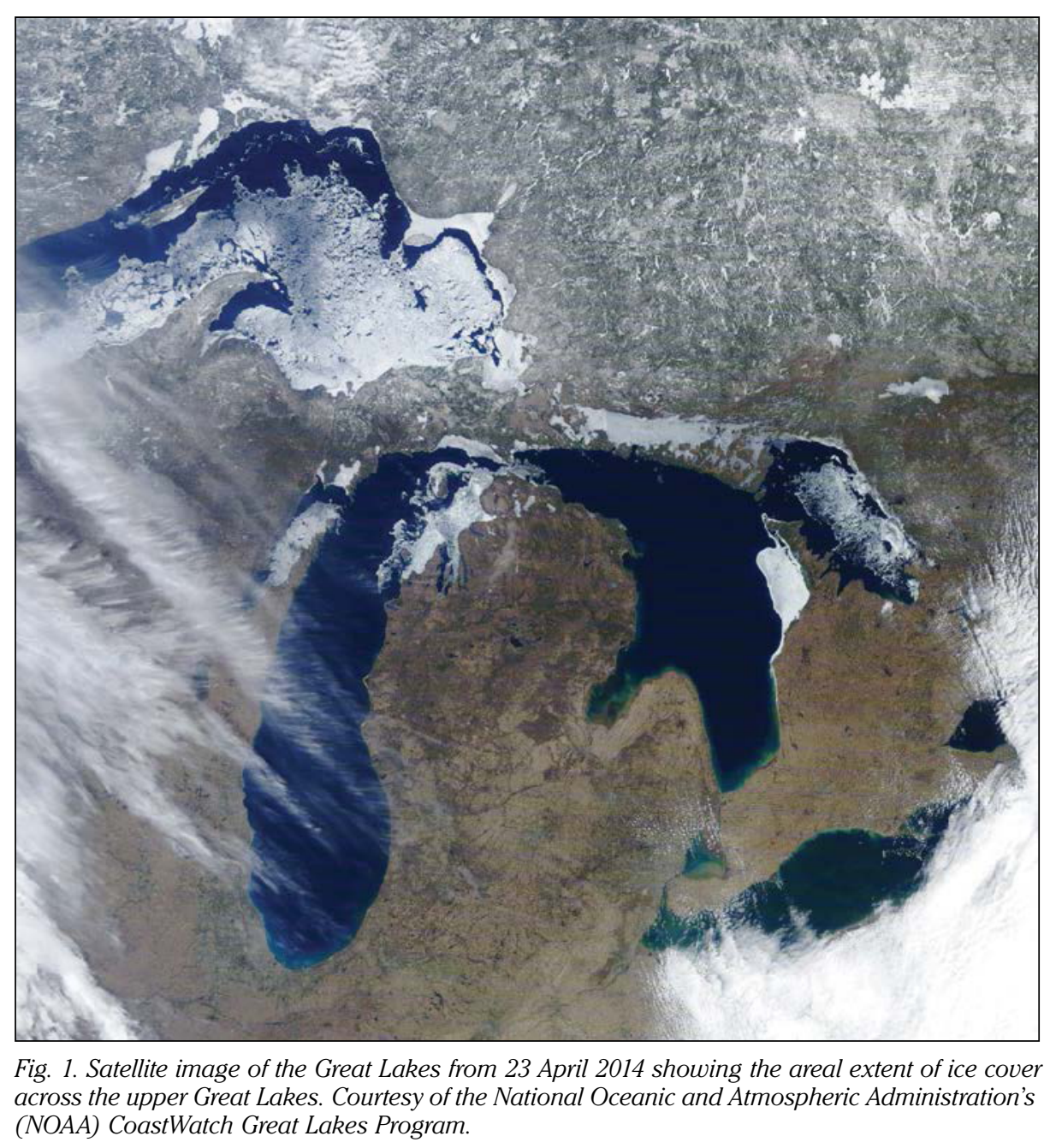

Fig. 1. Satellite image of the Great Lakes from 23 April 2014 showing the areal extent of ice cover across the upper Great Lakes. Courtesy of the National Oceanic and Atmospheric Administration's (NOAA) CoastWatch Great Lakes Program. increases in Great Lakes surface water temperatures and diminished ice cover (Figure 2), accelerated over-lake evaporation, and rapid water level declines [Assel et al., 2004; Gronewold and Stow, 2014; Van Cleave et al., 2014].

The recent extreme ice and temperature observations raise compelling questions about not only the extent to which the Great Lakes might transition to a new hydrologic regime characterized by cooler lake temperatures and rising water levels but also the extent to which such a regime might persist as the climate system evolves [Collins et al., 2010].

This paper is not subject to U.S. copyright. Published in 2014 by the American Geophysical Union. 


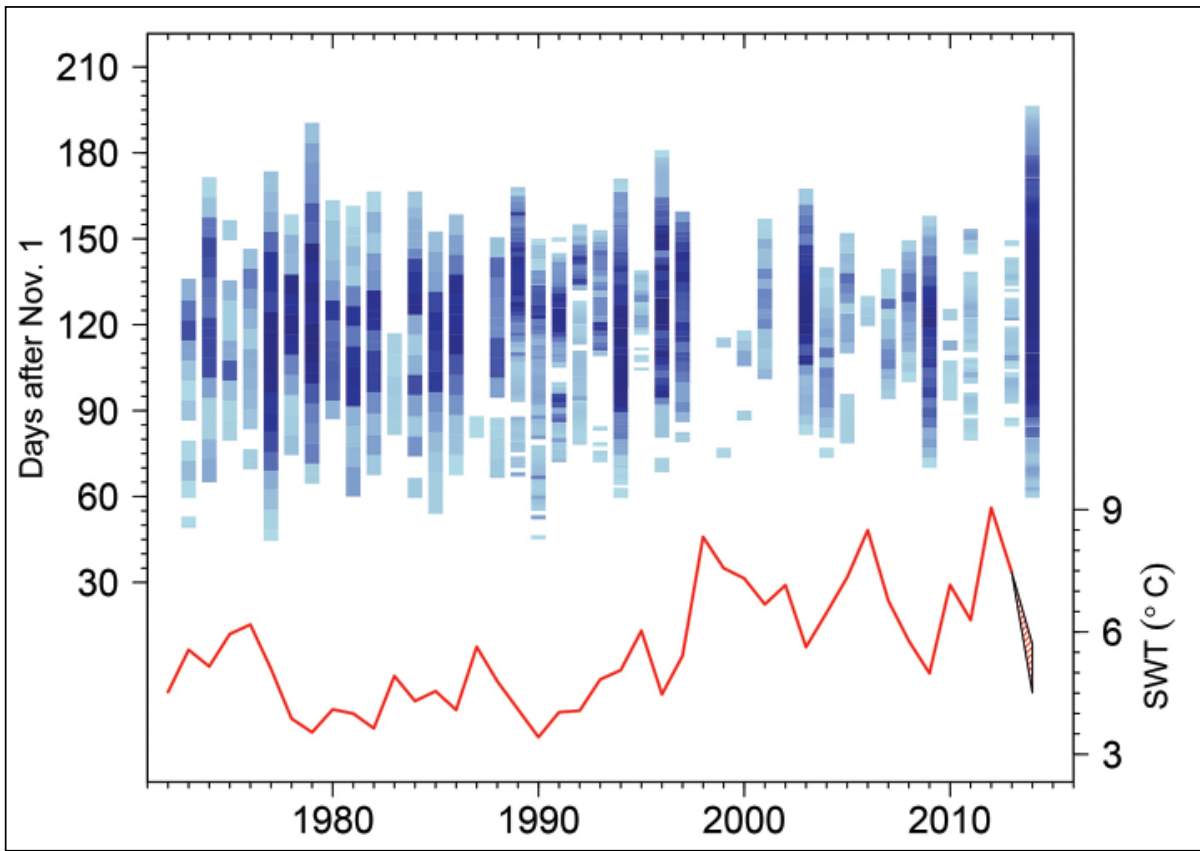

Fig. 2. Areal extent of daily ice cover (blue columns) and average annual lake-wide surface water temperature (SWT; red line) on Lake Superior from 1972 to 2014 (SWT value for 2014 is a projection, represented by a 90\% prediction interval). Each column corresponds to the ice season for the given calendar year. For example, the 1980 column represents ice cover data from roughly November 1979 through April 1980. The darkest shades of blue across all columns indicate ice cover near 100\%, whereas the lightest shades of blue indicate ice cover near 10\%. Ice cover and SWT data are adapted from the NOAA Great Lakes Ice Atlas project [Assel, 2003, 2005; Wang et al., 2012a, 2012b] and the NOAA Lake Thermodynamics Model [Croley and Assel, 1994], respectively.

\section{Acknowledgments}

This work was supported by NOAA, the U.S. Army Corps of Engineers, and the Great Lakes Restoration Initiative (administered by the U.S. Environmental Protection Agency). The authors thank Craig Stow, Brent Lofgren, and John Bratton for technical and editorial comments. This is NOAA-GLERL publication 1727

\section{References}

Assel, R. A. (2003), An electronic atlas of Great Lakes ice cover, winters: 1973-2002, NOAA atlas,
Great Lakes Environ. Res. Lab., Natl. Oceanic and Atmos. Admin., Ann Arbor, Mich. [Available at http://www.glerl.noaa.gov/data/ice/atlas/.]

Assel, R. A. (2005), Classification of annual Great Lakes ice cycles: Winters of 1973-2002, J. Clim., 18(22), 4895-4905.

Assel, R. A., F. H. Quinn, and C. E. Sellinger (2004), Hydroclimatic factors of the recent record drop in Laurentian Great Lakes water levels, Bull. Am. Meteorol. Soc., 85(8), 1143-1151, doi:10.1175/BAMS85-8-1143.

Blackmon, M. L., J. M. Wallace, N. C. Lau, and S. L. Mullen (1977), An observational study of the Northern Hemisphere wintertime circulation, J. Atmos. Sci., 34(7), 1040-1053.
Collins, M., et al. (2010), The impact of global warming on the tropical Pacific Ocean and El Niño, Nat. Geosci., 3(6), 391-397.

Croley, T. E., II, and R. A. Assel (1994), A onedimensional ice thermodynamics model for the Laurentian Great Lakes, Water Resour. Res., 30(3), 625-639.

Gronewold, A. D., and C. A. Stow (2014), Water loss from the Great Lakes, Science, 343(6175), 1084-1085.

Leshkevich, G. A., D. J. Schwab, and G. C. Muhr (1996), Satellite environmental monitoring of the Great Lakes: Great Lakes CoastWatch Program update, Mar. Technol. Soc. J., 30(4), 28-35.

McPhaden, M. J. (1999), Genesis and evolution of the 1997-98 El Niño, Science, 283(5404), 950-954. Van Cleave, K., J. D. Lenters, J. Wang, and E. Verhamme (2014), A regime shift in Lake Superior ice cover, evaporation, and water temperature following the warm El Niño winter of 1997-1998, Limnol. Oceanogr., in press.

Wang, J., X. Bai, H. Hu, A. H. Clites, M. Colton, and B. M. Lofgren (2012a), Temporal and spatial variability of Great Lakes ice cover, 1973-2010, J. Clim., 25(4), 1318-1329.

Wang, J., R. A. Assel, S. Walterscheid, A. H. Clites, and X. Bai (2012b), Great Lakes ice climatology update: Winter 2006-2011 description of the digital ice cover dataset, Tech. Memo. GLERL-155, 45 pp., Natl. Oceanic and Atmos. Admin., Silver Spring, Md.

-A. H. CliteS and J. WANG, Great Lakes Environmental Research Laboratory, National Oceanic and Atmospheric Administration (NOAA), Ann Arbor, Mich.; K. B. CAMPBELL, Cooperative Institute for Limnology and Ecosystems Research, University of Michigan, Ann Arbor; A. D. GRONEWOLD, Great Lakes Environmental Research Laboratory, NOAA, Ann Arbor, Mich., and Department of Civil and Environmental Engineering, University of Michigan, Ann Arbor; R. A. ASSEL, Great Lakes Environmental Research Laboratory, NOAA, Ann Arbor, Mich. (retired), and Cooperative Institute for Limnology and Ecosystems Research, University of Michigan, Ann Arbor; X. BAI, Cooperative Institute for Limnology and Ecosystems Research, University of Michigan, Ann Arbor; and G. A. LESHKEVICH, Great Lakes Environmental Research Laboratory, NOAA, Ann Arbor, Mich.; email: george.leshkevich@noaa.gov 